\title{
Managing Performance through Reward System
}

\author{
Sufyan Mehmood, Dr. Muhammad Ramzan, Muhammad Tahir Akbar \\ M.Phil scholar At Superior University Lahore Pakistan. \\ Director LibrariesLahore University of Management Sciences \\ M.Phil scholar At Superior University Lahore Pakistan.
}

\begin{abstract}
This research paper is about managing performance in an organization through reward system. This research enables to understand the current needs of an organization and its employees, their low productive behavior and the way how this behavior could be altered and how to make their performance boost up to the organizational needs and demands. The research was carried out through constructive analysis from different articles that base on reward system. Descriptive research design and exploratory research design were used to conduct the research.
\end{abstract}

Key Words: performance, Reward system, performance measurement, Performance management.

\section{Introduction}

This study sought to identify the key predictors of performance Management in a service organization in the almost all type of business organizations. The strongest predictors were found to be company satisfaction, the extent to which one's job takes advantages of talents and abilities, and the extent to which the organization emphasizes doing things right the first time. A work environment conducive to a continuous learning culture was also found to be highly associated with performance management.

The growing need of the management is to get the full potential out of your work force by providing them the skills and by proper coaching; motivation and appropriate appraisals, and this could only be possible when the employees are performing efficiently and up to the mark of achieving the organizational goals and mission. The management is getting aware of better understanding the growing needs of and employee and using different techniques and strategies, to overcome this gap through the most effective strategy and that is reward system. To manage performance of an individual or a group is that the management should have the skills to coach them in accordance to achieve the organizational goals and the best way is to give them a raise in something and it could be a monitory raise or some kind of recognition among others. Different organizations apply different strategies according to their respective environments, some may get influenced by more experienced or old employees and in response to that give a low performance behavior on the other hand sometime the organization makes reward system so strong that it gets out of hand for them to manage the organizational goals themselves. Therefore, the management performance system is a balance between the performance of an employee and the reward he/she gets from achieving the goals of the organization according to its mission.

According to Paul J stonich (1981) "corporations often find it difficult to carry out their strategies because they have executive compensation system that measure and reward performance in a way that ignores or even frustrates strategic thinking, planning, and action. In particular, rewards system rarely emphases the long neither run adequately, nor are they well-coordinated with the methods and objectives of other management systems". By this the writer says that, there are corporations that only emphases upon the reward system and ignore their strategic work therefore, the strategic plan of action gets ignored so as it affects the long run reward system and organizational goals, objectives as well.

ARNE L.Kalleberg, Karyn A. Loscocco; (Aging Values and Rewards, 1983 ) "by far most widely offered explanation age difference in job satisfaction focuses upon characteristics of the job itself: older workers are more satisfied than their younger counterparts because they actually have "better" or highly rewarded jobs". More experienced job holders enjoy better job rewards as compared to the less experienced which becomes a reason of dissatisfaction and low performance.

Rewards prove to be as a tool to increase performance and change behaviors in dissatisfies employees. Employees are the assets of the firm and they are the hands and brains through which the whole organizational process comes to life. Therefore, a fair reward system could build job satisfaction and productive behavior in an employee.

Herman Aguinis in his book entitled Performance Management, defined performance management as the "continuous process of identifying, measuring and developing the performance of individuals and teams and aligning performance with the strategic goals of the organization" (2007, p.2). this definition emphases upon 
performance management that it is a process of identifying the lacks of an employee or a group and enabling them to understand and develop their skills through better coaching and performance management that will lead towards achievement of organizational goals.

Reward system in not just about raise in the salary and bonuses, sometimes it includes both of these incentives, this also includes awards and recognition, reassignments, promotions and other reward programs.

Reward system is the necessity of the organization to retain and hire the desire employee to gain the competitive edge in such a competitive environment. Reward system motivating the employee work harder and faster as compare to other employee who has no reward system in their organization. Because worker need incentive to works hard and incentive plan under the reward system. Reward systems not only match organizational culture but also aligning with the strategy of organization.

According to Bahaudin G Mujtaba, (Coaching and Performance management: developing and inspiring leaders, pp 261, Para 2), "Reward system should be linked with goal-setting, employee development, competency measures, and team performance. This will decentralized the decision-making down the hierarchy to empower those performing the tasks. This will translate into better reward systems and better morale among employees. In order to create a competitive edge, many organizations are now doing more with fewer employees, so it is imperative that people are rewarded for using effective and ethical problem-solving and decision-making skills". Every organization has its own culture and reward system. Same reward system does not exist in another organization culture because business strategies are different and objective of organizations are also different. Therefore, organizations must be aware of using reward system that better fitsthe organization culture to increase the employee performance. Amazon.com is the best example of aligning reward system to its business strategy.

The reward system must be related to the company's strategy, business environment and culture. Now the question arises that how the reward system does fulfills employee needs and expectations? Managers of The Company want to hire the employee who is best fitted in organizational environment and works extra ordinary as compare to other employees. And it is possible only through the design of its reward system, (Wilson, Thomas, 1999).

ByWilson, Thomas, (1999), The reward system acts as a tool for testing the capabilities of an employee required for the job and could be a measure of checking the willingness to follow the organizational goals and so creates an opportunity to select the right candidate for the job.

Said Brian K. Boyd and Alain Salamin(Aug., 2001), Compensations offered by an organization give an advantage toits performance and for recruiting and retaining employees.

According to (Jason D. Shaw, Michelle K. Duffy, Eric M. Stark (Dec., 2001) "Grouped based rewards proves to become more effective than individual and creates corporations and team work efficient and effective which increases the performance of the organization".

Here are already researches that had been made, which signifies the body of observed data and supports that rewards are important for the performance of an employee's behavior. Many researchers have found that when the reward system that could be through pay, performance appraisals, promotions and recognition is raised which as in response becomes a raise in the performance of an employee as well; therefore to manage performance in an organization we should keep rewards under deep concerns. According to (Keller, R. T., \& Szilagyi, A. D (1976, dec)"In a study of unionized, incentive-paid workers in a manufacturing company, found that when pay has a high perceived probability of being contingent upon good performance, there is a better chance of good performance". This shows that less paid workers when expecting a high pay for performance give actually a good performance.

According to Rajiv D. Banker, Gordon Potter, Dhinu. (Jan., 2000), says "Empirically support for the hypothesized performance impacts of including nonfinancial measures in compensation plans is at best weak (Ittner and Larcker 1998b, 220). Ittner et al. (1997) analyzed the determinants of the use of nonfinancial measures in CEO compensation, but did not examine the performance impacts of such compensation plans". To manage the expenses of the organization it is must for the management to keep a balance of financial issues and it includes the rewards as well. Therefore, non-financial measures should be introduced and reward should be offered to employees so the employees so that performance could be maintained while expenses are also on hold.

Symons and Jacobs' (1995) study of a TQM-based reward system for production workers found that "operational performance improved, but it did not examine the effects on financial performance. Using crosssectional survey data, two studies found that self-reported use of manufacturing measures by managers had a positive impact on perceived performance in some manufacturing settings but not in others Ittner and Larcker Abernethy and Lillis (1995). A similar study found no such evidence Perera et al. (1997). None of these survey studies report the explicit use of nonfinancial measures in managerial compensation". This is a TQM study using the rewards as compensations where it has been examined that there has no study been made till now that reports the use of non-financial compensations that includes promotions, appreciations, and different incentives. 


\section{Methodology}

The research was carried out through constructive analysis from different articles that base on reward system. Emphasizing on performance through reward system, means to say how the reward are affected the performance of employee of any organizations at any level. Reward system in any organization play three different but related roles that are: motivating employee, retaining employee and attracting employee. Ability of organization keeps and hires desirable employee in competitive laborer market affected by reward system that is choosing by managers. The Descriptive research design and exploratory research design were used to conduct the research.

The problem is basically is that the employees are not commitment to their work, and also organizations not provide training and development plan to all employee. When peep deep into the problem result appear that it is occurring due to underutilization resources, corruption, political issues, work overload without being compensated for extra work. This in short is making employee de motivated and results in poor performance.

\section{Research statement of the paper is "Managing Performance through Reward System"}

Main objective of this paper is to investigate the important issues related to performance management. Particularly in this research study, investigate that whether low performances factors can be set off by eliminate those factors. So main objective is to check out that whether identify the key factors of performance management if improve it will increase overall performance of services sector.

\section{Conclusion}

It can be concluded that any organization's performance system should take into consideration the level of the service, which directly affects by employee benefits policy and the sustainability of the service. The findings of this paper showed that the most employees were dissatisfied with the incentive plan; Most of the respondents were also not satisfied with the safety standards of the organizations.

From research study it explored that incentive plans are a good way of bringing performance and loyalty for employee. Employees of services sectors that studiedfor research show a strong willingness of launching incentive plans for the high performance.

\section{Findings and Recommendation}

There are different suggestions that can be given to services sector. First of all talking about the job satisfaction as the average shows that the employees are not satisfied with their job that's why they don't performs well and the result was customers dissatisfied. There are many reasons behind that. They are not trained and also the over burden of work causes dissatisfaction in employees. So this can be removed by giving training to employees and also the job specification i.e. right person for the right job so that over burden from the employees can be removed.

Coming towards the second point that is job quitting the average shows that employees don't want to leave a permanent job. That's why everyone has showed that they will do job. In the third part everyone is asked about the salary package either they are satisfied or not. And almost everyone is not satisfied with their job. Work overload with a hectic routine without training is the reason.

- Organizations satisfy their customers by giving extra ordinary services with the help of employees to giving them performance based reward.

- Organizations focus on training and development of an employee that will enhance the overall performance of the organization.

\section{References}

[1]. Keller, R. T., \& Szilagyi, A. D. (1976, dec). Employee reaction to leader reward behavior. 19.No. 4,pp. 619-627.

[2]. Paul J stonich, using reward in implimenting strategy 1981, strategic management journal, vol 2 , Pg. 345

[3]. ARNE L.Kalleberg, Karyn A. Loscocco; Aging, Values and Rewards, 1983 Pg.79 Para.6 Vol. 48

[4]. Bahaudin G Mujtaba, (Coaching and Performance management: developing and inspiring leaders, pp 261, Para 2

[5]. Shaping a High-Performance Culture through HR and Reward System Design at Amazon.com, Wilson, Thomas, 1999,pp 3, Para 2.

[6]. Shaping a High-Performance Culture through HR and Reward System Design at Amazon.com, Wilson, Thomas, 1999,pp 4, Para2.

[7]. Joseph Harder, university of Virginia, organizational reward system, pp 1

[8]. Bahaudin G. Muztaba, coaching and performance management: developing and inspiring leaders, pp 269, para 3, table 13.1.

[9]. Balkin DB, Gomez-Mejia LR. 1987. toward a contingency theory of compensation strategy. Strategic Management Journal 8(2): $169-182$.

[10]. Kerr J. 1985. Diversification strategies and managerial rewards: an empirical study. Academy of Management Journal 28: 155 -179.

[11]. Hauser, John R., Duncan I. Simester, BirgerWernerfelt. 1994. Cus-tomer satisfaction incentives. Marketing Sci. 13(4) 327-350.

[12]. Ittner, C., and D. Larcker. 1995. Total quality management and the choice of information and reward systems. Journal of Accounting Research 33: 1-34. 
[13]. Greene, D., \&Lepper, M. R. Effects of extrinsic rewards on children's subsequent intrinsic in-terest. Child Development, 1974, 45, 1141- 1145 .

[14]. Ross, Michael. (1975). Salience of reward and intrinsic motivation. Journal of Personality and Social Psychology, 32, 245-254.

[15]. Ryan, Richard M., Mims, Valerie, \&Koestner, Richard. (1983). Relation of reward

[16]. Contingency and interpersonal context to intrinsic motivation: A review and test using cognitive evaluation theory. Journal of Personality and Social Psychology, 45, 736-750.

[17]. Keller, R. T., \& Szilagyi, A. D. (1976, dec). Employee reaction to leader reward behavior. 19.No. 4, pp. 619-627

[18]. Wilson, Thomas, 1999,Shaping a High-Performance Culture through HR and Reward System Design at Amazon.com, pp 4, Para2 